\title{
O direito fundamental à participação por meio da convenção de Aarhus em matéria ambiental como forma de implementar o estado constitucional cooperativo na figura do Amicus Curiae
}

\section{The fundamental right to participation by the Aarhus convention on environmental matters as a way to implement the cooperative constitutional state in the figure of Amicus Curiae}

Ana Carolina Couto Matheus Universidade Federal do Acre - UFAC

Resumo O escopo da pesquisa é analisar a Convenção de Aarhus em matéria ambiental sob o enfoque do Estado Constitucional Cooperativo, privilegiando o direito fundamental à participação. $\mathrm{O}$ objetivo geral é compreender a referida Convenção como forma de implementar o Estado Cooperativo para a proteção ambiental, na figura do amicus curiae. Objetivos específicos são: destacar que o governo brasileiro não ratificou a referida Convenção como corolário do Estado Ambiental Cooperativo; valorizar a construção teórica de Peter Häberle, que trata a cooperação internacional como responsabilidade internacional. Será utilizado o método indutivo, fonte bibliográfica, as técnicas do referente, conceito operacional, fichamento e da categoria.

Palavras-chave: Direito À Participação. Amicus curiae. Convenção de Aarhus. Estado Constitucional Cooperativo. Direito Fundamental.

Abstract The scope of the research is to analyze the Aarhus Environmental Convention under the Cooperative Constitutional State, focus- 
ing on fundamental right to participation. The general objective is to understand the said Convention as a way of implementing Cooperative State for environmental protection, in the form of the amicus curiae. Specific objectives are: to point out that the Brazilian government has not ratified the aforementioned Convention as corollary of the Cooperative Environmental State; The theoretical construction of Häberle, which treats international cooperation as international responsibility. It will be used the inductive method, bibliographic source, techniques of referent, operational concept and category.

Key-words: Right to Participation. Amicus curiae. The Aarhus Convention. Constitutional Cooperative State. Fundamental Right.

\section{INTRODUÇÃO}

Quanto às opções metodológicas e recortes epistemológicos, trata-se de um trabalho eminentemente bibliográfico, com fulcro em estudos explanatórios, que serão utilizados para investigar alguns temas com base em novas perspectivas e ampliar os estudos já existentes. A pesquisa emprega o método indutivo, a fonte bibliográfica, as técnicas do referente, do conceito operacional, do fichamento e da categoria.

O presente trabalho tem como objeto de pesquisa abordar a Convenção de Aarhus em matéria ambiental, por meio de uma análise crítica, no sentido de privilegiar o direito fundamental à participação, em especial a participação pública na tomada de decisões em questões ambientais. Também serão estudados importantes temas, como: o Estado Constitucional Cooperativo, o direito à informação, o acesso à justiça $\mathrm{e}$ a figura do amicus curiae.

Em 25 de junho de 1988, durante a $4^{\text {a }}$ Conferência Ministerial "Ambiente para a Europa", na cidade de Aarhus, localizada na Dinamarca, foi assinada a Convenção sobre o Acesso à Informação, Participação Pública na Tomada de Decisões e Acesso à Justiça em Questões Ambientais, denominada Convenção de Aarhus. A Convenção em epígrafe já está em vigor em vários países, bem como, na União Europeia, 
a partir do dia 30 de outubro de 2001, eis que já foi concluído o processo de ratificação da referida Convenção.

O tema escolhido para a presente pesquisa justifica-se pelo fato de que o processo de ratificação da Convenção de Aarhus já foi concluído, ou seja, a referida Convenção pode e deve ser utilizada pelo Supremo Tribunal Federal, como forma de implementação, por meio da importante figura do amicus curiae, do Estado Constitucional Cooperativo para a proteção ambiental.

A Convenção de Aarhus relaciona os direitos humanos aos direitos ambientais. Trata-se de uma Convenção inovadora, eis que somente com o envolvimento de todos os cidadãos é que será possível o desenvolvimento sustentável ser alcançado, destacando, no âmbito democrático, as necessárias interações entre as autoridades de diversos níveis e o setor público.

Como é cediço, o governo brasileiro ainda não ratificou a Convenção sobre o Acesso à Informação, Participação Pública na Tomada de Decisões e Acesso à Justiça em Questões Ambientais, denominada Convenção de Aarhus, como corolário do Estado Ambiental Cooperativo ou Estado Democrático e Ecológico de Direito. Além de um acordo internacional em matéria ambiental, a Convenção de Aarhus considera também o princípio da transparência, o princípio da credibilidade e o princípio da responsabilização que se aplicam às instituições e também a todos os indivíduos.

A brilhante construção teórica de Peter Häberle privilegia o marco de referência da pesquisa em tela, segundo a qual a cooperação internacional é tratada como responsabilidade internacional ou para o mundo, por ser um pressuposto comum de toda a humanidade. Nesse contexto urge aprofundar os debates sobre esse importante assunto em testilha, com o objetivo principal de compreender a referida Convenção em virtude da necessidade de acesso à informação como forma de implementar o Estado Constitucional Cooperativo para a proteção ambiental, na figura do amicus curiae. Caracterizam os objetivos específicos deste trabalho: destacar que o governo brasileiro não ratificou a referida Convenção como corolário do Estado Ambiental Cooperativo; valorizar a 
construção teórica de Peter Häberle, que trata cooperação internacional como responsabilidade internacional.

Esta pesquisa destaca como questões centrais: Qual a importância da Convenção de Aarhus sobre o acesso à informação, a participação do público no processo de tomada de decisão, o acesso à justiça em matéria ambiental e o amicus curiae? Quais os aportes teóricos? O que se deve entender por cooperação internacional em matéria ambiental no ordenamento jurídico brasileiro? O que se deve entender por Estado Constitucional Cooperativo?

Para tanto, a pesquisa em epígrafe foi organizada em quatro partes. A primeira parte trata do Direito Fundamental à Participação e a figura do amicus curiae. A segunda parte analisa a Convenção de Aarhus, também denominada Convenção sobre o Acesso à Informação, Participação Pública na Tomada de Decisões e Acesso à Justiça em Questões Ambientais. A terceira parte estuda o Estado Constitucional Cooperativo. A quarta e última parte do trabalho observa a cooperação internacional em matéria ambiental no âmbito do ordenamento jurídico brasileiro.

\section{$1 \mathrm{O}$ Direito FUNDAMENTAL À PARTICIPAÇÃo E A Figura do Amicus CURIAE}

A democracia existe onde há a participação na ordem estatal, "onde há a codecisão, deliberação comum, pelo povo ou por pessoas por ele escolhidas" (PONTES DE MIRANDA, 1945, p. 158). O Estado Democrático de Direito deve propiciar a todos os cidadãos condições de igualdade. É fundamental permitir a atuação efetiva e concreta de todos os seus jurisdicionados, oferecendo-lhes a possibilidade de desenvolvimento integral, atuação nos processos decisórios em todas as searas, e liberdade de participação crítica no processo político (CANOTILHO, 1999, p. 283).

Os diferentes e os plurais interesses da sociedade precisam se fazer presentes junto ao Estado no processo de tomada de decisões. Se o Estado é incapaz de realizar direitos fundamentais e atender aos reclamos da sociedade, é necessário abrir espaço para uma representação 
não oficial. Häberle (2002, p. 43-44) explica que toda a sociedade é potencialmente apta a participar do processo de interpretação constitucional e, quanto mais pluralista, tanto mais abertos devem ser os critérios hermenêuticos.

Na concepção de Häberle (2002, p. 45) apenas uma ampla participação de todas as pessoas, potências públicas e todos os grupos permitiria maior legitimidade às decisões, possibilitando um debate plural acerca das controvérsias. $\mathrm{O}$ debate deve ser viabilizado no sentido de permitir que as minorias tenham espaços para defender os seus direitos. A abertura procedimental é imprescindível no panorama atual. Deve-se permitir que todas as pessoas, as potências públicas e todos os grupos, todas as forças produtivas de interpretação participem do processo de revelação constitucional, possibilitando a realização da democracia e dos direitos fundamentais (GUERRA FILHO, 1999, p. 5).

O instituto do amicus curiae é instrumento de realização do princípio democrático e dos direitos fundamentais, permitindo a concretização do processo justo, ou seja, um processo capaz de realizar a entrega da tutela jurisdicional justa e adequada.

A abertura do processo judicial relaciona-se ao panorama da pós-modernidade, sendo parte do direito de participação no Estado Democrático de Direito. Os direitos fundamentais não se restringem aos expressamente positivados na ordem jurídica constitucional, mas todos aqueles que a eles são equiparados, por força Constitucional. A figura do amicus curiae tem sua noção cada vez mais ampliada, porque a participação de interessados no debate judicial é o resultado do princípio democrático, da necessidade dos cidadãos de expressar anseios e pontos de vista, que convergem com a utilidade da Corte em conhecer a realidade da sociedade.

Amicus curiae exerce a função de integração, muito relevante ao Estado de Direito, como instrumento de democracia e da realização dos direitos fundamentais, contribui para a realização da prestação jurisdicional mais segura e completa, bem como, garante a realização de um processo justo. A necessidade de solução dos diversos casos concretos fortalece a influência das decisões judiciais, aumentando o poder dos 
magistrados, que, diante dos fatos da vida, tendem a cumprir as decisões dos tribunais na criação do direito (SCALIA, 1997, p. 39).

O Brasil adotou o sistema da civil Law, porém, atualmente, observa-se influência da commom Law nas decisões proferidas pelo Supremo Tribunal Federal, o que representa um aumento da participação popular na tomada de decisões judiciais. Entre os institutos que permitem a participação do cidadão na construção da opinião das Cortes Supremas em matéria constitucional, destaca-se a figura do amicus curiae, ou também denominado "amigo da Corte". Trata-se de mecanismo processual descrito no artigo $7^{\circ}$., § $2^{\circ}$. da Lei n. 9.868/1999.

Na concepção de Becker (2015), amicus curiae é uma expressão latina que significa "amigo da Corte" ou "amigo do Tribunal". Trata-se de pessoa ou entidade estranha à causa, que vem auxiliar o Tribunal, provocada ou voluntariamente, oferecendo esclarecimentos sobre questões essenciais ao processo.

A Lei n. 9.868/1999 trouxe a previsão do instituto do amicus curiae de forma mais ampla, na ação direta de inconstitucionalidade, na ação declaratória de constitucionalidade e nos demais processos de efeito concreto. Trata-se de passo essencial ao reconhecimento do amicus curiae no Brasil. Antes dessa lei, o amicus curiae somente colaborava de maneira informal no processo de jurisdição constitucional, sem a representatividade devida, apenas juntava memoriais fora do curso do processo, na capa dos autos, ainda não integrava o processo de jurisdição constitucional (GONTIJO; SILVA, p. 87).

Após o advento da referida Lei, o Supremo Tribunal Federal passou a admitir a atuação do amicus curiae no curso do processo e permitir sua integração na jurisdição constitucional pela juntada de documentos, mas sem a possibilidade de interferência oral nas discussões da Corte. A sustentação oral do amicus curiae demorou para ser reconhecida pela Suprema Corte, somente após a pressão social para que as decisões se aproximassem cada vez mais dos interesses da sociedade, por meio das ADIs 2.675 e 2.777 é que o Supremo permitiu a interferência de terceiros nos processos abstratos de constitucionalidade e a considerá-los amicus curiae. 
A Lei n. 10.259/2001, que instituiu os Juizados Especiais Federais, estabelece no artigo $14, \S 7^{\circ}$. a possibilidade de atuação processual do "amigo da Corte". O amicus curiae é um elemento de intervenção cidadã no processo constitucional, permite o acesso à justiça no sentido mais amplo. É um elemento de conexão entre a sociedade e o Supremo Tribunal Federal.

É necessário permitir mecanismos para a participação de terceiros, pluralizando o debate em todas as searas processuais, como fruto da consolidação do pensamento democrático. A figura do amicus curiae viabiliza a participação de interessados que, embora não tenham legitimidade, são destinatários diretos ou mediatos da decisão a ser proferida. Amicus curiae atua no sentido de universalização e realização dos direitos fundamentais e do princípio democrático, permitindo a entrega da efetiva tutela jurisdicional.

A ideia de sociedade aberta ou pluralista desenvolvida por Häberle (2002, p. 37-45), permitindo a participação de todos os membros da sociedade no processo de interpretação da Constituição, é ínsita ao panorama da pós-modernidade e ao Estado Democrático de Direito. Amicus curiae permite a inserção de novos instrumentos de pluralização ao debate, é instrumento de democracia, universaliza e realiza direitos fundamentais e o princípio democrático, permitindo a entrega da efetiva tutela jurisdicional.

\section{CONVENÇÃo SOBRE ACESSO À INFORMAÇÃO, PARTICIPAÇÃo DO PÚBLICO NO PROCESSO DE TOMADA DE DECISÃo E ACESSO À justiça em matéria ambiental (Convenção de Aarhus)}

A Convenção de Aarhus, ou Convenção da Comissão Econômica para a Europa das Nações Unidas (CEE/ONU) sobre o Acesso à Informação, Participação Pública na Tomada de Decisões e Acesso à Justiça em Matéria de Ambiente, foi assinada na cidade de Aarhus, localizada na Dinamarca, no dia 25 de junho de 1998, durante a $4^{\text {a }}$ Conferência Ministerial "Ambiente para a Europa". 
A referida Convenção já está em vigor em vários países, bem como, na União Europeia, a partir do dia 30 de outubro de 2001, eis que já foi concluído o seu processo de ratificação, dessa forma a Convenção em testilha pode e deve ser utilizada pelo Supremo Tribunal Federal, no sentido de implementar o Estado Cooperativo para a proteção ambiental, na figura do amicus curiae.

É uma Convenção inovadora, pois estabelece relações entre os direitos ambientais e os direitos humanos, assumindo que o desenvolvimento sustentável só poderá ser atingido com o envolvimento de todos os cidadãos e dando relevo às interações que se devem estabelecer entre o público e as autoridades, aos mais diversos níveis, em um contexto democrático. Entretanto, o governo brasileiro ainda não ratificou a Convenção de Aarhus ou Convenção sobre o Acesso à Informação, Participação Pública na Tomada de Decisões e Acesso à Justiça em Questões Ambientais como corolário do Estado Ambiental Cooperativo ou Estado Democrático e Ecológico de Direito.

O marco de referência desta pesquisa privilegia a brilhante construção teórica de Häberle, segundo a qual a cooperação internacional é tratada como responsabilidade internacional ou para o mundo, por ser um pressuposto comum de toda a humanidade. É fundamental aprofundar os debates acerca do importante assunto em epígrafe, em especial o instituto do amicus curiae, com o objetivo principal de compreender a referida Convenção como forma de implementar o Estado Cooperativo para a proteção ambiental.

Nos termos do artigo $1^{\circ}$., a referida Convenção objetiva "contribuir para a proteção do direito que qualquer indivíduo, das gerações atuais ou futuras, tem de viver num ambiente adequado à sua saúde e bem-estar, cada Parte garantirá os direitos de acesso à informação, à participação do público e ao acesso à justiça, em matéria de ambiente", sendo esses três aspectos considerados como os seus três pilares fundamentais.

O tripé da Convenção de Aarhus: Acesso à Informação, Participação Pública e Acesso à Justiça, constitui parte integrante do Direito Internacional do Meio Ambiente contemporâneo, além de transpor que 
os limites de consensos regionais sobre o meio ambiente devem ser tutelados pelos Estados.

Para Sgarioni e Rammê (2012, p. 736), justificam-se os três pilares da Convenção de Aarhus no domínio do ambiente, porquanto além de aumentar a qualidade das decisões e reforçar a sua aplicação, contribuem para a sensibilização do público para as questões ambientais, ensejando a possibilidade de manifestação das preocupações e permitindo às autoridades públicas tomar conhecimento das preocupações manifestadas. Nesse sentido:

Porquanto, mesmo com a aceitação da Convenção de Aarhus, ainda será necessária a admissão de valores e regras existentes em outros tratados internacionais que porventura o Estado brasileiro ainda não tenha aderido, tudo com vistas a uma efetiva ética ambiental preocupada com as graves questões que envolvam o meio ambiente e consagrando a abertura do Estado para o rumo de um Estado Ambiental Cooperativo (SGARIONI; RAMMÊ, 2012, p. 737).

Nos termos da Convenção de Aarhus (art. $4^{\circ}$. e a $9^{\circ}$.), esse tripé sustenta basicamente os seguintes direitos: o direito de ter o público em geral o acesso à informação que desejar, incluindo o direito de ter cópias da documentação que contém a informação solicitada: sem que seja necessário declarar um interesse na questão; na forma solicitada, a menos que: seja razoável que a autoridade pública apresente a informação de outra forma; nesse caso, devem ser expostas as razões que o justificam; a informação esteja disponível ao público de outra forma (art. $4^{\circ}$., parágrafo $1^{\circ}$.).

Tal informação deve ser prestada de forma rápida, o mais tardar no prazo de um mês a contar da apresentação do pedido, a menos que o volume e a complexidade da informação justifiquem um prolongamento desse prazo até dois meses após a apresentação do pedido, devendo o requerente ser informado do prolongamento do prazo, bem como, das razões que o justifiquem (art. $4^{\circ}$., parágrafo $2^{\circ}$.). 
O direito de ser o público envolvido informado de forma adequada na fase inicial de um processo de tomada de decisões em matéria ambiental, por meio de aviso público ou individualmente, designadamente: da atividade proposta e do pedido relativamente ao qual será tomada uma decisão; da natureza das eventuais decisões ou do projeto de decisão; da autoridade pública responsável pela adoção da decisão; do procedimento previsto, incluindo como e quando pode ser comunicadas: as informações sobre o início do processo e as informações acerca das possibilidades de participação do público.

Também as informações sobre o momento e o local de realização das audiências públicas previstas; a indicação da autoridade pública junto da qual seja possível obter a informação relevante e à qual essa informação tenha sido confiada para exame pelo público; a indicação da autoridade pública ou qualquer órgão oficial para o qual possam ser enviados comentários ou questões, assim como o prazo de apresentação desses mesmos comentários ou questões; e a indicação da informação ambiental disponível relevante para a atividade proposta; e ainda, do fato de a atividade estar sujeita a um procedimento transfronteiras de avaliação de impacto ambiental (art. $6^{\circ} .2^{\circ}$.).

$\mathrm{O}$ direito de ser garantido, em conformidade com o disposto na legislação nacional de cada Estado-parte, o direito de interpretar recurso junto aos tribunais, ou de outro órgão independente e imparcial instituído por lei, a qualquer pessoa que considere que o pedido de informações por si apresentado nos termos do disposto do artigo $4^{\circ}$. foi ignorado, indevidamente recusado, no todo ou na parte, objeto de uma resposta incorreta, ou que não tenha recebido um tratamento consentâneo com o disposto no mesmo artigo (art. $9^{\circ}$.).

Na concepção de Mazzuoli e Ayala:

Apesar de se tratar de um acordo inicialmente regional em matéria ambiental, pode-se dizer que os princípios que provêm de Aarhus têm conotação global, notadamente pelo fato de versar um tema de interesse de toda sociedade internacional, já delineado no Princípio 10 da Declaração do Rio de Janeiro sobre Meio Ambiente 


\begin{abstract}
e Desenvolvimento em 1992. Em outras palavras, ao abrir aos cidadãos o acesso à informação mantida pelas autoridades públicas, a Convenção de Aarhus dá um passo importante em termos de superação da democracia formal pela democracia substancial. Além do mais, ao permitir a Convenção o ingresso de "qualquer outro Estado (...) que seja membro das Nações Unidas (...) após a aprovação em Reunião das Partes (art. 19, parágrafo $3^{\circ}$.), está ela contribuindo para catalisar os esforços da sociedade internacional rumo àquilo que se pode chamar de "controle externo" das atividades estatais no que tange à proteção efetiva do meio ambiente em escala global" (MAZZUOLI; AYALA, 2012, p. 312).
\end{abstract}

Para Mazzuoli e Ayala (2012, p. 313), a garantia de acesso à informação e de intervenção nos processos de formação das decisões constituem, desse modo, elementos indispensáveis para o fim de se viabilizar padrões mais elevados de qualidade de vida; padrões que sejam o resultado de escolhas públicas e privadas, individuais ou coletivas, e que são, e devem ser sempre, escolhas bem informadas, segundo o estado de conhecimento disponível. De acordo com Basterra (2006, p. 10), o direito de acesso à informação pública não se confunde com o direito à informação, já que este é um direito individual a favor apenas do particular, que o exerce da forma que melhor o satisfizer. $\mathrm{Na}$ concepção de Moraes:

O direito a receber informações verdadeiras é um direito de liberdade e caracteriza-se essencialmente por estar dirigido a todos os cidadãos, independentemente de raça, credo ou convicção político-filosófica, com a finalidade de fornecimento de subsídios para a formação de convicções relativas a assuntos públicos (MORAES, 2000, p. 162).

O direito de acesso à informação pública é direito fundamental que pesa sobre o Estado, no âmbito dos três poderes e em seus três níveis de descentralização autônoma, de fazer ser efetivo o direito dos 
cidadãos para consentir a um bem coletivo que é a informação estatal (BASTERRA, 2006, p. 21).

O artigo 13 da Convenção Americana dos Direitos Humanos trouxe ao ordenamento jurídico pátrio um reforço do que já era resguardado pela Constituição Federal, isto é, o reconhecimento formal do direito em receber informação e dela usufruir da maneira que melhor the convier. O artigo 19 da Declaração Universal dos Direitos dos Homens de 1948 assegura o direito de acesso à informação pública, como direito essencial do ser humano, bem como, a imperiosidade de procurar, receber e transmitir dados que estão relacionados com o exercício da cidadania.

A Convenção de Aarhus é inovadora, uma vez que estabelece relações entre os direitos ambientais e os direitos humanos, assumindo que o desenvolvimento sustentável só poderá ser atingido com o envolvimento de todos os cidadãos e dando relevo às interações que se devem estabelecer entre o público e as autoridades, aos mais diversos níveis, num contexto democrático.

Por conseguinte, o acesso à informação possui dois objetivos: “o desenvolvimento pessoal do indivíduo pela obtenção de conhecimento e a transparência do Estado que possua uma cultura de acesso livre às informações que sejam de interesse social" (SCHLACKE; SCHARADER; BUNGE, 2009 apud DIZ e DISCACCIATI, 2015, p. 78).

Em 2014, ocorreu na Holanda a $5^{\text {a }}$ Reunião das Partes da Convenção, onde foi adotada a Declaração de Maastricht. Trata-se de Declaração que reafirma a transparência como motor da democracia ambiental. Diversos fóruns e trabalhos apresentados em Portugal procuram implementar em relação aos diferentes níveis as decisões tomadas para que seja possível exercer uma cidadania ativa e responsável, por intermédio de um conjunto de meios de intervenção que manifestam práticas de boa governança, nas quais os princípios da transparência e da subsidiariedade são garantidos.

Em Portugal, em 2016, ocorreram duas fases de consulta na elaboração do $5^{\circ}$. Relatório de Implementação Nacional da Convenção de Aarhus, sobre um texto inicial que se baseou no relatório anterior de 2014. Nesse sentido, Diz e Discacciati (2015, p. 78) explicam que a 
censura e a limitação de acesso à informação pelo governo anestesiam a atividade popular, visto que não se podem demandar novas medidas e políticas persistindo a ignorância sobre o que está realmente ocorrendo naquela comunidade ou, em maiores dimensões, naquele país.

A Convenção de Aarhus não constitui apenas um acordo internacional em matéria ambiental, mas considera também o princípio de responsabilização, o princípio da transparência e o princípio da credibilidade que se aplicam tanto às instituições quanto aos indivíduos.

\section{ESTADO CONSTITUCIONAL COOPERATIVO: PROBLEMA E CONCEITO}

Na obra "Pluralismo y Constitución: estudios de Teoría Constitucional de la sociedad abierta" (2002), a cooperação internacional é tratada por Häberle como responsabilidade internacional ou paz para o mundo, já que é um pressuposto comum de toda a humanidade e deve ser observada em questões de vital importância, como nos casos de matérias-primas, energia e alimentos. Todavia, o paradigma do "Estado Constitucional Cooperativo" foi desenvolvido primeiramente por Peter Häberle, entre 1977 e 1978, por ocasião da publicação do ensaio com o mesmo nome e da contribuição para a discussão no Simpósio dos Professores alemães de Direito Público, ocorrido em 1977, na Basileia.

Häberle afirma, no Capítulo 1 da obra "Estado Constitucional Cooperativo" (2007, p. 32), que "o tipo de Estado Constitucional ocidental livre e democrático não é, como tal, imutável”. Séculos foram necessários para se moldar o "conjunto" dos elementos estatal e democrático, de direitos fundamentais individuais e, por fim, sociais e culturais, e o futuro continuará a desenvolvê-los. Nesse sentido:

O Estado Constitucional ocidental é concebido como tipo atual, e sua existência como tal é que permite, nesse quadro, modificações em uma extensão consideravelmente variável: decisiva é sua estrutura constituída, ou seja, juridicamente delimitada, e decisiva é a sua estrutura aberta - tanto para o dentro como para fora. Ela é garantida pela democracia pluralista, por direitos funda- 
mentais, por elementos da divisão de poderes que devem ser ampliados no âmbito da sociedade, e por um Poder Judiciário independente (HABERLE, 2007, p. 2).

A “Cooperação será, para o Estado Constitucional, uma parte de sua identidade que ele, no interesse da "transparência constitucional", não apenas deveria praticar como, também, documentar em seus textos jurídicos, em especial nos documentos constitucionais" (HÄBERLE, 2007, p. 3-4). Para Häberle (2007, p. 4), Estado Constitucional Cooperativo é o Estado que justamente encontra a sua identidade também no Direito Internacional, no entrelaçamento das relações internacionais e supranacionais, na percepção da cooperação e responsabilidade internacional, assim como no campo da solidariedade. Ele corresponde, com isso, à necessidade internacional de políticas de paz. Häberle (2007, p. 10) explica que "o Estado Constitucional Cooperativo é a resposta interna do Estado Constitucional ocidental livre e democrático à mudança no Direito Internacional e ao seu desafio que levou a formas de cooperação".

Logo "o Estado Constitucional e o Direito Internacional transformam-se em conjunto. O Direito Constitucional não começa onde cessa o Direito Internacional. Também é válido o contrário, ou seja, o Direito Internacional não termina onde começa o Direito Constitucional" (HÄBERLE, 2007, p. 11). Contudo, o que é próprio do "Estado Constitucional Cooperativo"?

Abertura para relações internacionais com efeito de impor medidas eficientes no âmbito interno (permeabilidade), também no acento da abertura global dos direitos humanos (não mais cerrados no domínio reservado) e de sua realização "cooperativa". Potencial constitucional ativo, voltado ao objetivo (e elementos isolados nivelados) de realização internacional "conjunta" das tarefas como sendo da comunidade dos Estados, de forma processual e material. Solidariedade estatal de prestação, disposição de cooperação para além das fronteiras: assistência ao desenvolvimento, proteção ao meio ambiente, combate aos terroristas, fomento à cooperação internacional também a nível jurídico privado (Cruz Vermelha, Anistia Internacional). Dessa forma, Häberle destaca: 
O Estado constitucional cooperativo se coloca no lugar do Estado constitucional nacional. Ele é a resposta jurídico-constitucional à mudança do Direito Internacional de direito de coexistência para o direito de cooperação na comunidade (não mais sociedade) de Estados, cada vez mais imbricada e constituída, e desenvolve com ela nela o "direito comum de cooperação". A Sociedade aberta dos interpretes da Constituição tona-se internacional! (HÄBERLE, 2007, p. 71).

Um Estado Cooperativo é aquele que não mais se apresenta como um Estado Constitucional voltado para si mesmo, mas que está disponível como referência para os outros Estados Constitucionais membros de uma comunidade. Para Christine Oliveira Peter da Silva (2011), "se este Estado Constitucional Cooperativo tiver como fórmula básica um modelo de concretização da Constituição", seja no plano da jurisdição constitucional, seja no plano da dinâmica concretizadora das demais funções de Poder: processo legislativo e processo político, "que esteja atenta para os aportes das decisões das Cortes Constitucionais de outros países" (Direito Constitucional Comparado) e, principalmente encontre, no plano interno, fórmulas de ressonância das decisões das Cortes Internacionais.

\section{COOPERAÇÃo INTERNACIONAL NO ÂMBITO DO ORDENAMENTO JURÍDICO BRASILEIRO EM MATÉRIA AMBIENTAL}

Cooperação representa um dos princípios da Constituição da República Federativa do Brasil de 1988, previsto no artigo $4^{\circ}$., inciso IX, e no parágrafo único. O parágrafo $2^{\circ}$. do artigo $5^{\circ}$. prevê que os direitos e garantias expressos nessa Constituição não excluem outros decorrentes do regime e dos princípios por ela adotados, ou dos tratados internacionais em que a República Federativa do Brasil seja parte.

O termo "cooperação" começou a ganhar ênfase no plano internacional com a Carta das Nações Unidas (art. $1^{\circ}$., parágrafo $3^{\circ}$.), quando ali se previu ser um dos propósitos da ONU conseguir uma cooperação internacional para resolver os problemas internacionais de caráter eco- 
nômico, social, cultural ou humanitário, e "para promover e estimular o respeito aos direitos humanos e às liberdades fundamentais para todos, sem distinção de raça, sexo, língua ou religião" (MAZZUOLI, 2011, p. 620-621). A Carta Magna (1988) mais enfaticamente disciplinou a cooperação "econômica e social" nos artigos 55 e 56, assim redigidos:

\section{Artigo 55}

Com o fim de criar condições e bem-estar, necessárias às relações pacíficas e amistosas entre as Nações, baseadas no respeito ao princípio da igualdade de direitos e da autodeterminação dos povos, as Nações Unidas favorecerão:

a) níveis mais altos de vida, trabalho efetivo e condições de progresso e desenvolvimento econômico e social;

b) a solução dos problemas internacionais econômicos, sociais, sanitários e conexos: a cooperação internacional, de caráter cultural e educacional; e

c) o respeito universal e efetivo dos direitos humanos e das liberdades fundamentais para todos, sem distinção de raça, sexo, língua ou religião.

\section{Artigo 56}

Para a realização dos propósitos enumerados no artigo 55, todos os membros da Organização se comprometem a agir em cooperação com esta, em conjunto ou separadamente (grifo da autora).

Em relação à cooperação para fins de proteção e melhoramento do meio ambiente, o Princípio 24 da Declaração de Estocolmo sobre o Meio Ambiente Humano (1972) dispôs que:

Todos os países, grandes ou pequenos, devem empenhar-se com espírito de cooperação e em pé de igualdade na solução das questões internacionais relativas à proteção e melhoria do meio. É indispensável cooperar mediante acordos multilaterais e bilaterais e por outros meios apropriados, a fim de evitar, eliminar ou reduzir, e controlar eficazmente os efeitos prejudiciais que as 
atividades que se realizam em qualquer esfera possam acarretar para o meio, levando na devida conta a soberania e os interesses de todos os Estados.

No Fórum de Siena, ocorrido entre os dias 17 a 21 de abril de 1990, preparatório para a Conferência do Rio de Janeiro de 1992, o dever de cooperação entre Estados para a preservação do meio ambiente ficou assim colocado:

A obrigação de cooperar manifesta-se como um dever de agir de boa fé, a fim de atingir-se uma meta de interesse geral, em face dos Estados diretamente envolvidos, representando também o interesse da comunidade internacional no seu conjunto. Traçar uma lista de ações precisas a serem levadas a cabo é uma tarefa impossível, pois cada situação deve ser avaliada à luz das características específicas em cada caso. Contudo, podem-se citar algumas ações do tipo de cooperação, referentes aos Estados. Trata-se, em particular, das obrigações relativas à informação, à notificação, à assistência mútua e à negociação. Tais ações, frequentemente, completam os sistemas de proteção do meio ambiente elaborados pelo Direito Internacional.

O tema voltou à tona na Declaração do Rio de Janeiro sobre Meio Ambiente e Desenvolvimento (1992), tendo o seu Princípio 7 estabelecido que "os Estados irão cooperar, em espírito de parceria global, para a conservação, proteção e restauração da saúde e da integridade do ecossistema terrestre". No âmbito do MERCOSUL, cabe destacar o Acordo Quadro sobre Meio Ambiente do MERCOSUL, celebrado em Assunção, no Paraguai, em 22 de junho de 2001, e ratificado pelo Brasil em 9 de outubro de 2003, que resulta, logo em seu segundo considerando, a necessidade de "cooperar para a proteção do meio ambiente e para a utilização sustentável dos recursos naturais, com vistas a alcançar a melhoria da qualidade de vida e o desenvolvimento econômico, social e ambiental sustentável”. 
Na concepção de Mazzuoli e Ayala, a saber:

Todas essas normas internacionais serão paradigmas para a cooperação internacional em matéria de proteção ambiental, tal como previsto por diversas legislações contemporâneas, e, no Brasil, pela Lei 9.605/1998, nos seus artigos 77 e 78 . Tais dispositivos refletem, portanto, o engajamento do Estado brasileiro para com a proteção do meio ambiente, nas ordens nacional e internacional, especialmente (mas não exclusivamente) na seara da cooperação para fins penais, de acordo com as regras nacionais sobre o tema e com os tratados internacionais dos quais a República Federativa do Brasil é parte (MAZZUOLI; AYALA, 2012, p. 300).

Na concepção de Mazzuoli e Ayala (2012), se não existissem os artigos 77 e 78 da Lei dos Crimes Ambientais em nossa ordem jurídica, a obrigação do Estado brasileiro de cooperar (não somente em matéria penal) com outros países se faria presente, uma vez que o Brasil é parte dos principais tratados em matéria de proteção do meio ambiente, que têm inclusive status diferenciado na ordem jurídica interna (no nosso entender esse status é de "norma constitucional"), por pertencerem à categoria de tratados de direitos humanos lato sensu. Para Mazzuoli e Ayala (2012), outro motivo é ter a Constituição Federal de 1988 consagrado, no seu artigo $4^{\circ}$., II e IX, os princípios da prevalência dos direitos humanos e da cooperação entre os povos para o progresso da humanidade, em que indubitavelmente se inclui a proteção do meio ambiente.

O Estado brasileiro se obriga, por meio de lei, a cooperar internacionalmente para a preservação do meio ambiente, ou seja, pode-se afirmar que tanto a Convenção de Aarhus, em âmbito internacional, quanto a Lei $\mathrm{n}^{\mathrm{o}}$. 10.650, de 16 de abril de 2003, em âmbito nacional, representam um avanço à preservação ambiental para as presentes e as futuras gerações. 


\section{CONSIDERAÇões FINAIS}

Quanto às opções metodológicas e recortes epistemológicos, tratou-se de um trabalho eminentemente bibliográfico, com fulcro em estudos explanatórios, no qual foram utilizados para investigar alguns temas com base em novas perspectivas e ampliar os estudos já existentes. A pesquisa empregou o método indutivo, a fonte bibliográfica, as técnicas do referente, do conceito operacional, do fichamento e da categoria. Por conseguinte, o presente trabalho chegou aos resultados a seguir descritos.

Considerando as duas questões gerais que nortearam o trabalho em epígrafe, a primeira diz respeito ao fato de que é cediço que o Brasil não é signatário da Convenção de Aarhus, mas que gerou repercussões no ordenamento jurídico brasileiro, no que tange ao acesso à informação ambiental. A segunda questão consistiu em rever a Convenção de Aarhus sob a ótica do Estado Constitucional Cooperativo, privilegiando o direito fundamental à participação pública na tomada de decisões em matéria ambiental, bem como o acesso à informação, o acesso à justiça e a figura do amicus curiae. Com vistas a esse fim, percorreu-se, do ponto de vista do marco de referência, a bibliografia de relevância já tornada pública em relação ao tema de estudo, a Constituição da República Federativa do Brasil de 1988, a legislação infraconstitucional e as contribuições doutrinárias.

A Convenção de Aarhus ou Convenção sobre o Acesso à Informação, Participação Pública na Tomada de Decisões e Acesso à Justiça em Questões Ambientais, foi assinada na cidade de Aarhus, na Dinamarca em 1998, durante a 4 a Conferência Ministerial “Ambiente para a Europa”, já está em vigor em vários países, bem como, na União Europeia, a partir de 30 de outubro de 2001. Como o processo de ratificação da Convenção de Aarhus já foi concluído, a referida Convenção pode e deve ser utilizada pelo Supremo Tribunal Federal, como forma de implementação de Estado Cooperativo para a proteção do meio ambiente, na figura do amicus curiae.

É uma Convenção inovadora, pois estabelece relações entre os direitos ambientais e os direitos humanos, assumindo que o desenvol- 
vimento sustentável só poderá ser atingido com o envolvimento de todos os cidadãos e dando relevo às interações que se devem estabelecer entre o público e as autoridades, aos mais diversos níveis, em um contexto democrático. Entretanto, o governo brasileiro ainda não ratificou a Convenção de Aarhus como corolário do Estado Democrático e Ecológico de Direito ou Estado Ambiental Cooperativo.

Constitui acordo internacional em matéria ambiental que considera o princípio de responsabilização, o princípio da transparência e o princípio da credibilidade que se aplicam tanto aos indivíduos quanto às instituições. $\mathrm{O}$ marco de referência da pesquisa em epígrafe privilegiou a brilhante construção teórica de Peter Häberle, segundo a qual a cooperação internacional é tratada como responsabilidade internacional ou para o mundo, por ser um pressuposto comum de toda a humanidade. Nesse contexto, urge aprofundar os debates sobre esse importante assunto em tela, com o objetivo principal de compreender a referida Convenção como forma de implementar o Estado Cooperativo para a proteção ambiental, na figura do amicus curiae.

Os objetivos específicos deste trabalho foram alcançados, eis que a pesquisa destacou que o governo brasileiro não ratificou a referida Convenção como corolário do Estado Ambiental Cooperativo e valorizou a construção teórica de Häberle relativa à cooperação internacional como responsabilidade internacional. As questões centrais desta pesquisa foram analisadas por meio de aportes teóricos, bem como, pelo estudo da legislação atinente aos temas abordados.

Em relação às hipóteses, a primeira caracterizada pelo direito fundamental à participação e a figura do amicus curiae foi estudada na primeira parte do trabalho. A segunda hipótese caracterizada pela importância da Convenção de Aarhus sobre o acesso à informação, a participação do público no processo de tomada de decisão, o acesso à justiça em matéria ambiental, foi amplamente estudada na segunda parte do trabalho que descreve a Convenção de Aarhus e analisa as questões mais importantes relacionadas à matéria ambiental. A terceira hipótese abordou o conceito de Estado Constitucional Cooperativo. A quarta e última hipótese da pesquisa estudou o que se deve entender por 
cooperação internacional em matéria ambiental no ordenamento jurídico brasileiro.

$\mathrm{O}$ ordenamento jurídico brasileiro ainda apresenta uma lacuna acerca do tema da participação pública na tomada de decisões relacionadas à matéria ambiental e do direito de acesso à informação, visto que o Brasil não faz parte da Convenção Aarhus. Não obstante, a Convenção de Aarhus pode e deve ser utilizada pelo Supremo Tribunal Federal, como forma de implementação do Estado Cooperativo para a proteção do meio ambiente, na figura do amicus curiae. Como se constatou, o Estado brasileiro se obriga, por meio de lei, a cooperar internacionalmente para a preservação do meio ambiente, ou seja, pode-se afirmar que tanto a Convenção de Aarhus, em âmbito internacional, quanto a Lei n. 10.650/2003, em âmbito nacional, representam um avanço para a preservação do meio ambiente.

É fundamental ressaltar que mais do que o dever de cooperar, é a obrigação de informar, representa a pedra de toque do sistema contemporâneo das normas (internacionais e internas) de cunho ambiental, notadamente das que expressamente garantem o ingresso dos cidadãos à justiça em matéria ambiental, bem como, o acesso à informação e, principalmente, o direito fundamental à participação pública no processo de tomada de decisões nas questões ambientais, destacando a importância da figura do amicus curiae.

\section{REFERÊNCIAS}

\section{BASTERRA, Marcela. EI derecho fundamental de acesso a la información} pública. Buenos Aires: Lexis Nexis Argentina, 2006.

BECKER, Rodrigo Frantz. Amicus Curiae no novo CPC. Disponível em: $<$ https://www.jota.info/artigos/amicus-curiae-no-novo-cpc>. Acesso em: 6 abr. 2017.

BRASIL. Constituição (1988). Coletânea de Legislação e Jurisprudência. Vademecum, 9. ed. São Paulo: Saraiva, 2016. 
BRASIL. Lei $\mathbf{n}^{\mathbf{0}} \mathbf{1 0 . 6 5 0}$, de 16 de abril de 2003. Coletânea de Legislação e Jurisprudência. Vademecum, 9. ed. São Paulo: Saraiva, 2016.

CANOTILHO, José Joaquim Gomes. Direito Constitucional e Teoria da Constituição, 3. ed. Coimbra: Almedina, 1999.

DIZ, Jamile Bergamaschine Mata; DISCACCIATI, Ana Clara Gonçalves. Acesso à informarão ambiental: por um novo paradigma de participação. Revista Direito e Liberdade - DRL - ESMARN, v. 17, n. 3, p. 71-113, set./dez. 2015. ISNN impresso 1809-3280; ISSN eletrônico 2177-1758.

GONTIJO, André; SILVA, Christiane Oliveira Peter da. O papel do amicus curiae no Estado Constitucional: mecanismo de acesso da transdisciplinariedade no processo de tomada de decisão constitucional. In: Anais do XIX Encontro Nacional do CONPEDI realizado em Fortaleza - CE nos dias 9, 10, 11 e 12 de junho de 2010, p. 84-99. Disponível em: <http://www.conpedi.org. br/>. Acesso em: 6 mai. 2017.

GUERRA FILHO, Willis Santiago. Processo Constitucional e Direitos Fundamentais. São Paulo: Celso Bastos e Instituto Brasileiro de Direito Constitucional, 1999.

HÄBERLE, Peter. Hermenêutica Constitucional. A sociedade aberta dos intérpretes da constituição: contribuição para a interpretação pluralista e "procedimental" da constituição. Tradução Gilmar Ferreira Mendes. Porto Alegre: Sergio Antonio Fabris Editor, 2002.

. La sociedad abierta de los intérpretes constitucionales: una contribución para la interpretación pluralista y "procesal" de la Constitución. Academia. Traduccíon Xabier Arzoz Santisteban (Universidad del País Vasco). Revista sobre enseñanza del Derecho. Ano 6, Número 11, 2008, ISSN $1667-4154$, p. $29 / 61$.

Estado Constitucional Cooperativo. Tradução Marcos Augusto Maliska e Elisete Antoniuk. Rio de Janeiro: Renovar, 2007.

. Pluralismo y constitución: estudios de Teoría Constitucional de la sociedad abierta. Traducción de Emilio Likunda. Madrid: Tecnos, 2002.

MAZZUOLI, Valério de Oliveira; AYALA, Patryck de Araújo Cooperação internacional para a preservação do meio ambiente: o direito brasileiro e a 
Convenção de Aarhus. Revista Direito GV 15. São Paulo 8(1) 12, jan./jun. 2012, p. 297-328.

MORAES, Alexandre de. Direitos humanos fundamentais: teoria geral, comentários aos artigos $1^{\circ}$. a $5^{\circ}$. da Constituição da República Federativa do Brasil, doutrina e jurisprudência, 3. ed. São Paulo: Atlas, 2000.

NUNES, Alexandre Augusto Pereira. Direito fundamental de acesso à informação. Democracia, Estado Democrático de Direito, República e Controle Social. São Paulo: Lumen Juris, 2014.

ONU. Resolução da Assembleia da República nº 11/2003. Convenção sobre Acesso à Informação, Participação do Público no Processo de Tomada de Decisão e Acesso à Justiça em Matéria de Ambiente. Disponível em: <http:// www.gddc.pt/sii/docs/rar11-2003.pdf>. Acesso em: 12 abr. 2017.

PONTES DE MIRANDA, Francisco Cavalcante. Democracia, liberdade, igualdade: os três caminhos. São Paulo: J. Olympo, 1945.

SCALIA, Antonin. A matter of interpretation. Federal Courts and the law. New Jersey: Princenton, 1997.

SGARIONI, Márcio Frezza; RAMMÊ, Rogério Santos. Estado ambiental cooperativo e o Supremo Tribunal Federal com ator jurídico na valorização dos acordos internacionais em matéria ambiental. Revista Eletrônica Direito e Política, Programa de Pós-Graduação Stricto Sensu em Ciência Jurídica da UNIVALI. Itajaí, v. 7, n. 1, 1 . quadrimestre de 2012. ISSN 1980-7791. Disponível em: <http://www.univali.br/direitoepolítica>. Acesso em 15 mar. 2017.

SILVA, Christine Oliveira Peter da. Estado constitucional cooperativo. Direito Público. Porto Alegre: Síntese; Brasília: Instituto Brasiliense de Direito Público, 2006, v. 3, n. 12 (abr./mai./jun.), p. 5-20.

. Estado constitucional cooperativo: o futuro do Estado e da interpretação constitucional sob a ótica da doutrina de Peter Häberle. Disponível em: $<$ http://buscalegis.ccj.ufsc.br>. Acesso em: 17 abr. 2017.

. Transjusfundamentalidade: diálogos transnacionais sobre direitos fundamentais. Curitiba: CRV, 2014.

SILVA, José Afonso. Comentário contextual à Constituição, 4. ed. São Paulo: Malheiros, 2007. 


\section{Sobre a autora}

\section{Ana Carolina Couto Matheus}

Doutoranda em Ciência Jurídica pela UNIVALI - SC. Mestre em Direito Processual pela UNIPAR - PR. Especialista em Direito Tributário pela UnP - RN. Pós-graduada em Direito Constitucional pela UVB - PR. Bacharel em Direito pela TOLEDO - SP. Professora Adjunta, nível 3, do Curso de Graduação em Direito da UFAC. Advogada. Consultora jurídica. Orientadora. Conferencista. Autora de diversas obras jurídicas. Pesquisadora.

E-mail: carolcoutomatheus@hotmail.com.

Submetido em: 14-06-2017

Aceito em: 07-11-2017 